Abstracta Iranica Abstracta Iranica

Revue bibliographique pour le domaine irano-aryen

Volume 29 | 2008

Comptes rendus des publications de 2006

\title{
In Search of Cultural Identity Monuments and Artifacs of the Sasanian Near East 3rd to 7th Century A.D. New York, 2006, 210 p. (Bibliotheca Persica)
}

\section{Barbara Kaim}

\section{(2) OpenEdition}

1 Journals

\section{Édition électronique}

URL : http://journals.openedition.org/abstractairanica/26762

DOI : 10.4000/abstractairanica.26762

ISSN : 1961-960X

Éditeur :

CNRS (UMR 7528 Mondes iraniens et indiens), Éditions de l'IFRI

\section{Édition imprimée}

Date de publication : 15 mai 2008

ISSN : 0240-8910

\section{Référence électronique}

Barbara Kaim, «In Search of Cultural Identity Monuments and Artifacs of the Sasanian Near East 3rd to 7th Century A.D. New York, 2006, 210 p. (Bibliotheca Persica) », Abstracta Iranica [En ligne], Volume 29 | 2008, document 115, mis en ligne le 15 septembre 2008, consulté le 26 septembre 2020. URL : http:// journals.openedition.org/abstractairanica/26762 ; DOI : https://doi.org/10.4000/abstractairanica. 26762

Ce document a été généré automatiquement le 26 septembre 2020.

Tous droits réservés 


\title{
In Search of Cultural Identity Monuments and Artifacs of the Sasanian Near East 3rd to 7th Century A.D. New York, 2006, 210 p. (Bibliotheca Persica)
}

\author{
Barbara Kaim
}

1 Cet ouvrage est organisé en quatre chapitres. Le premier présente les aspects de l'art sassanide et de la propagande royale profondément enracinés dans les anciennes traditions proche-orientales, comme l'image du taureau ailé à tête humaine, les scènes de combat et de chasse ainsi que les images et pratiques liées au royaume du surnaturel. Le deuxième chapitre examine la diversité culturelle liée à la géographie et aux événements historiques. Les différents types d'inhumation, la céramique et les cachets illustrent la diversité régionale, culturelle et religieuse dans le royaume des Sassanides. Certaines constatations de l'A. concernant la diversité régionale semblent un peu hasardeuses en raison de la maigreur des sources. Les reliefs en stuc de Bandian ont-ils un style et une iconographie distinctes, ou bien cette impression n'est-elle qu'une illusion résultant de l'état de recherches? Dans ces stucs, les scènes du combat au moins ne semblent être ni nouvelles ni particulières.

2 La troisième partie traite de la diffusion de l'art et de l'iconographie sassanides « dans les pays de l'Est et de l'Ouest ». Les réflexions sur l'identité culturelle sassanide constituent le dernier chapitre, à la fin duquel l'A. exprime son espoir que de nouvelles découvertes et de nouvelles recherches complèteront notre connaissance de la culture de cette période. 
INDEX

Thèmes : 3.2.3. Séleucides, Parthes et Sassanides

\section{AUTEURS}

BARBARA KAIM

Université de Varsovie 